\title{
Organized Reframing Process with Video Ethnography: A Case Study of Students' Design Project for New Interface Concept from Research to Visualization
}

\author{
Katsuhiko Kushi \\ Goshokaido-cho, Matsugasaki, Sakyo-ku, Kyoto, \\ 606-8585, Japan \\ kushi@kit.ac.jp
}

\begin{abstract}
Ethnographical research is a recent trend in design profession field, but its open-ended approach does not always bring effective solutions, especially when a novice design student executes it. Inspired by Jacob Buur's video ethnography, the author revised the approach and applied it to a design project sponsored by a corporation. The project goal set by the company was vague enough for students to lose a consistent direction, however, with this method they could find underlying needs and created a set of attractive solution ideas to the client company.

This report will describe how the project went and generate results, and finally, discuss the possibility of design with video ethnography.
\end{abstract}

Keywords: Video ethnography, interface design, GUI, user need.

\section{Introduction}

An observation to find user needs is a typical start for a design project, especially in universities. Similar to design process in industry, it is often difficult for design students to connect research results to design solutions. If a project is focused on some specific product area, such as a mobile phone or ticket-vending machine, students execute research with confidence. In that case, they may be able to properly identify needs and make good designs based on those needs. But, if a project aims at giving a general outline of a wider product category, such as products with a small LCD display, as we were assigned to, the foci of their research and attention can easily be blurred and scattered. In such a case, the following of analysis will not give a clear definition of user needs and inevitably results in generation of poor ideas.

KOTO corporation in Kyoto city, that was planning to make wide use of a low-cost graphic chip, asked us to visualize new interface designs for daily electronic products with LCD displays since the company needed to show future design images of prospective customer manufactures' products to promote the chip. An LCD display with finger touch technology is becoming a major interface platform of daily electronic products. However, when we see beautiful and dynamic graphic design on the display, the products always have specially made graphic chips on the circuit boards of the products, and they require a large investment to make. So, although people already seem to be accustomed to seeing and using a small display interface, there are only few products that 
have full color and dynamic displays, such as handheld game devices, and mobile phones including the iPhone. Other than these exceptions, common electronic products, such as fax-phones, remote controllers or microwave ovens, still have monochrome and static LCD displays. If a cheap and wide range of application graphic chip can be available for many products with small displays, how will interface design change and how will interactions between the system and people change? This question was the theme of this design project given by our client company.

\section{Organized Research and Analysis}

The theme above seemed to be wide and vague enough for students to fall into the typical failure. To avoid making a group of disconnected ideas, we tried to organize a consistent design process from the observation phase to prototyping. Ethnographical user research is now an emerging method in product development, owing to its potential for finding latent user needs [1]. Among those methods, the video ethnography method introduced by Jacob Buur et al. is characterized by its strength in allowing project members and observation subjects to share in the creative process of finding and interpreting problems, and defining design goals [2][3]. Although Burr's video ethnography method aims to achieve deep user participatory design environment, we focused on its collaborative aspects in regard to young team members in the design process, and applied it to this project, to establish a common interface concept for various products with small LCD displays.

The project team consisted of eight design students from Kyoto Institute of Technology (KIT) and the author, as a project leader. To cover such a wide product range in a relatively short period, we first made a list of subject products and allotted each member a portion of observations work to be conducted with video cameras. The list included 12 kinds of electronic product with small displays. To obtain a good contrast in our study, we also included 6 non-electronic products that users felt a strong attachment to. The followings are our steps in the early phase of the project.

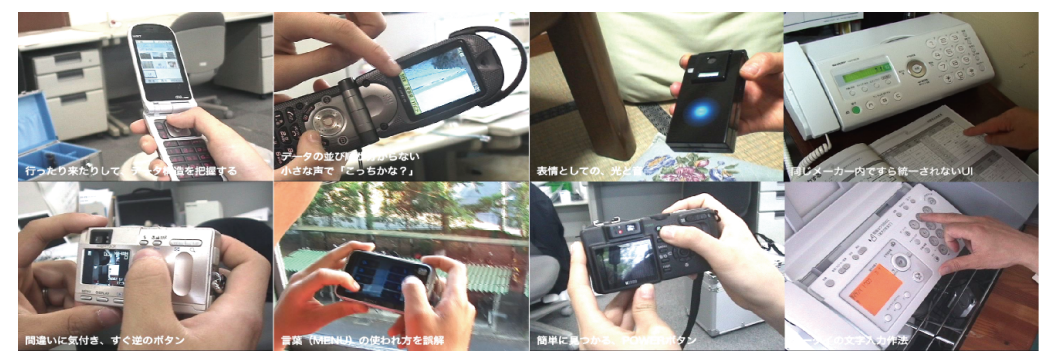

Fig. 1. Examples of subject products

\section{Observation:}

- A group of one to three design students visited the users' daily environment at, for example, their home, office, or on the street. They watched and recorded their activity using the subject products with digital video cameras. 
- When possible, we asked users to try to use the latest product that was brought by us, such as a digital camera with a touch screen control panel.

- When possible, we asked users to show the product they were most attached to and show how they are using them.

\section{Video analysis:}

- A group of two to three reviewed assigned video data. A group had a combination of at least one observer who shot the video, and one non-observer of the visit.

- Watching video on a PC (Macintosh), they tried to find interesting points, including users' failures, unique usages, contextual meanings, and so on. While finding those points, they were encouraged to discuss with each other. In most cases, a discussion started from an observer's explanation of a users' situation, followed by a non-observer's questions that livened up their dialogue. Those discussions watching video data generated new findings and understandings of interactions between users and products.

- To record their findings, we made short video clips that clearly represented the points. The number of clips reached to 199 for electronic products with displays and 43 for products in the contrast group.

\section{Collaborative editing of observation results:}

- Following Buur's video ethnographical method, we played a "video card game" where we invited engineers from our client company. Necessary preparations involved making physical photo cards representing each edited clip. There were 242 cards in total.

- Before playing, we reviewed and shared all the video clips with simple explanations made by clip editors.

- Based on the Kawakita's KJ method, together with the visitors, we sorted all the cards into several groups of categories, and put names on each card group [4]. This time, we created 12 categories of findings. The followings are the names of the categories.

\section{Love at first sight / Drifting / Exploring / Guessing / Stress / Feeling of wrongness / Forgetting / Compromise / Trust / Exclusive selection / Adapting / Special treatment}

- We arranged the photo card groups on a large sheet of paper. Then we could see some relationships among all groups fall along two axes. The first axis showed how much users made use of products, and the other showed how much users understood the products.

- With those categories and the 2 axes, we got an overall view of all problems found through the observation and the video analysis. Namely, we got a video card map of problematic situations. In the map, we found there was a time flow of user experience with machines.

\section{Reframing by Needs Mining:}

- From the map mentioned above, we could get an overview of a broad range of interaction problems people were facing everyday. However, it only described a visible phenomenon, and it did not indicate latent design needs for new concepts. So, we still needed more thorough interpretations of the map. 


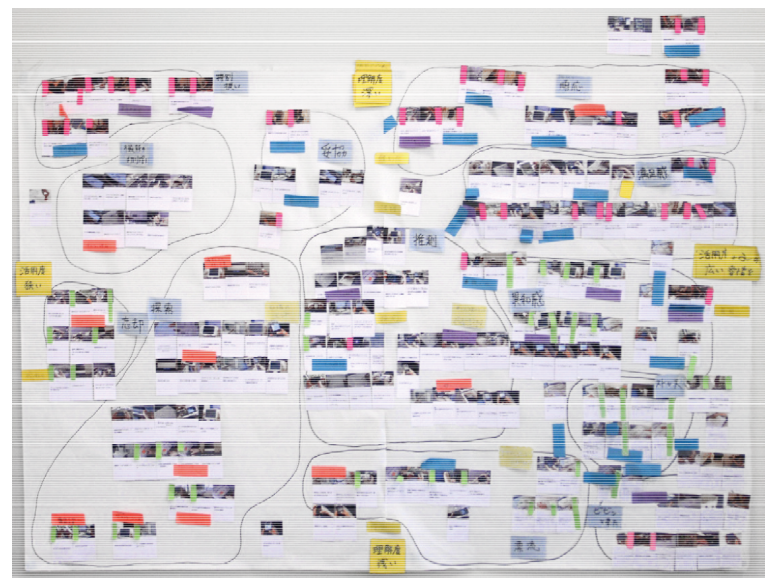

Fig. 2. The map of video card game

- In this step, each member was to collect four cards from each category to express more definite needs, rather than problems. They put four cards on a sheet of A4 paper, and wrote the title of the need at the top, and the simple explanations on the bottom. We called this sheet "a card family." Individual students made the card families and created 39 family sheets in total.

- Through the "card family" step, each team member was to find underlying realities that existed under multiple categories and product types. This activity required individual creativity and a thorough interpretation and reframing of phenomena.



Fig. 3. 2 examples of the card family

After making card families, we put all of them on a table, and we reordered family sheets as we did in the video card game. As a result, we established 6 categories of card families. The following are the titles of the categories.

Small home but fun place / Minimum distance among mental model, expression, and operation / Natural expression matching with machine / Feel of the space on GUI / Message through GUI / Important GUI elements 


\section{Design frame from understanding the structure of needs}

Looking at the groups of card families, we noticed a structured relationship between them. We rearranged the group accordingly and finally made a concept diagram, which showed an interface goal with small LCD displays on various products and its constituent factors and hierarchy.

The goal we established was the 'fun-pact interface.' Fun-pact was a term coined to combine 'fun' and 'compact.' With this title, we wanted to propose fun interactions, despite the fact that the product itself was a daily appliance, and usually made at low-cost with relatively simple functions. 'Compact' does not only describe the size of the product, but also the lower complexity of the product functions and concepts.

This main keyword stems from the observations in which we saw that users had struggled to understand and manipulate small displays because of their poor communication design that uses static expressions and too many layers of command structures. So, the keyword aimed at the interface design opposite of the boring and complex current state of small interactive displays.



Fig. 4. The first diagram of the structure of needs

The Fun-pact interface design consists of two major factors. One factor addresses the user's experience by "encourage the user's positive motivation to drive (Driving motivation)." The second factor addresses the user's acceptance of information, by "making system expressions friendly to the user's mind set (Friendly expression)".

In the former keyword, we aimed to provide a design, which could evoke the user's positive emotional response when touching the products. This would generate the users' own customizations and rules. Users' customizations and rules were expected to make products fun to use and encouraged the users' positive attachment to them. The latter keyword - compact - was meant to achieve an interface mechanism using natural and direct graphical expressions, easily understandable to users. Reducing user's cognitive loads should be crucial to peace of mind in use.

In the concept diagram, the two major factors of the "fun-pact interface" have two additional sub-factors respectively. "Driving motivation" factor has "an attractive 
opening screen evoking the feeling of driving" and "a fun feeling when moving back and forth in a menu structure." "Friendly expression" factor consists of "expressions unique to machines" and "coaching communication rather than teaching."

\section{Visualizing Keywords as Interface Design}

Over the course of a few months, in an organized manner we gradually constructed our deeper understanding of the project theme and people's needs in terms of using daily electronic appliances with small displays.

After establishing the design frame, we moved to the phase of visualization. The following process that we executed, seemed to be based on a standard product design process. Each step is as follows.

- Sharing solution image of each design frame keyword using photo collages.

- Setting target-products to redesign.

- Setting simple user scenarios based on observations.

- Generating conceptual ideas for each item through brainstorming sessions.

- Selecting potential ideas to refine.

- Making demo-animations of the ideas with Adobe Flash.

\section{Finalizing the Design Frame as a System to Present to Outside People}

At the same time when we were making demo-animations, we also had been rethinking the frame itself. Since the design frame existed mainly for a project core, and

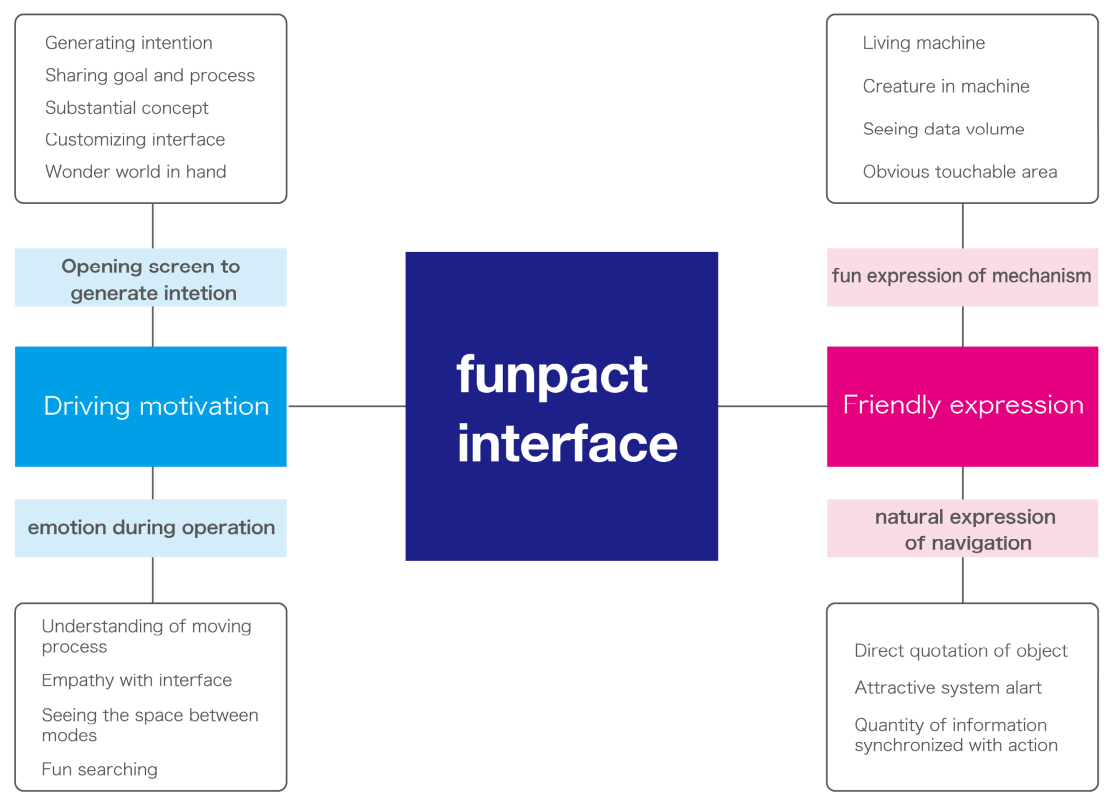

Fig. 5. The final diagram of the structure of needs with solution ideas 
resources of ideation for all members inside the project, the keywords were not elaborated for outsiders to understand. We found that the demo-animation not only expressed the keywords, but also communicated each one's more concrete message. Then, we made a matrix chart and diagram to include ideas and revised keywords. In order to present ideas and their structure as a whole, we also made a viewer, where all ideas were presented using an inter-net browser.
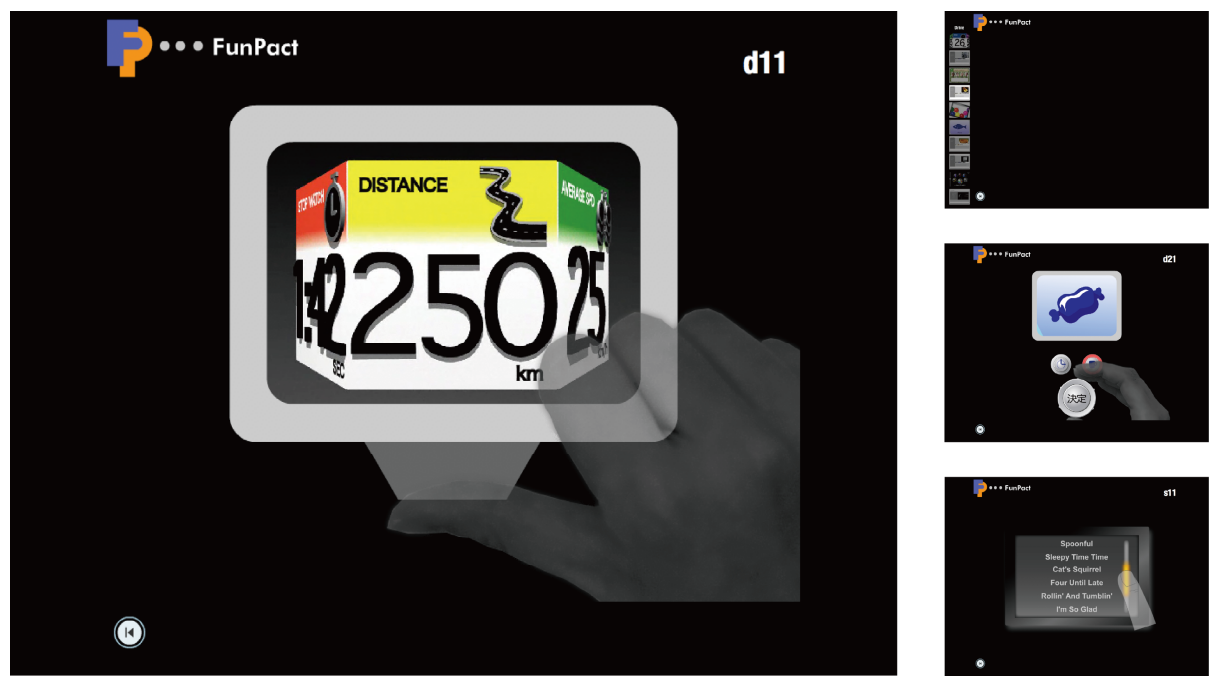

Fig. 6. The solution ideas on the viewer

\section{Effects of Video Ethnography Method in a Student Project}

Rapid ethnography is regarded as a methodology used in the business field in order to explore the contextual needs of people. Usually professionals, like ethnographers, usability engineers, or interaction designers, conduct ethnographical research to see certain activities of some product domain. Those professionals are flexible in fitting methods to various circumstances. In our project, researchers were university design students who were not expected to be flexible, and the project theme was abstract. The video ethnography method introduced by Buur is definitely one of the more rapid ethnography methods. It has has a better organized approach in order to invite interdisciplinary people, including subject users, to participate in the development process. We found some merits of video ethnography in different purposes. The merits of video ethnography for a student project are:

- It can cover various people and product areas at the same time.

- Video data keeps important facts, even if an inexperienced observer overlooks them at the site.

- It is possible to explore and find needs by watching video. This feature is effective, especially when observation time is limited. 
- Video analysis by means of editing short video clips by a team of observers and a non-observers gives not only a wider view of phenomena, but also a deeper understanding through their discussions.

- Video card game can give opportunities for all attendees to share all analysis results, and to collaboratively realize a broad range of problematic phenomena.

- Deeper interpretation of the phenomena, which sometimes indicates the underlying needs, can be achieved through the activity of making card family sheets.

- By sorting card families, students can find a structure of needs, and consequently, they can generate a conceptual design frame for a given project theme.

\section{Conclusion}

This case study has reported how video ethnography can be applied in a student project, and how can the process can provide them an environment to create GUI design solutions for small LCD displays on various daily products. From the experimental application, it can be concluded that video ethnography has a large potential to enable novice system developers, like design students, to find latent user needs and create design ideas based on these needs even with very abstract (or not well defined) theme.

In Japan, most manufacturing companies, as well as design courses in universities, do not have video ethnography specialists inside their organizations, despite the fact that the use of focus group interviews and questionnaire surveys has been well established practice. Nobody can deny the importance of triangulation, however, the fact is that only very few corporations are using ethnography for their third point of view. Since video ethnography can be started with novice observers, the author assumes that this method can be widely applicable not only to the field of design education, but also the field of business in Japan.

\section{Acknowledgement}

The author would like to thank Kozy Kubota of KOTO Corporation for giving us the chance to try this experimental approach on the project. Akitoshi Wada for providing coaching to students. I would also like to thank all of the students from Kyoto Institute of Technology who participated in this project, for their enthusiasm. This work was sponsored by the New Energy and Industrial Technology Development Organization (NEDO) in Japan.

\section{References}

1. Sherry Jr., J.F.: Ethnography, Design, and Customer Experience; An Anthropologist's Sense of it All. In: Squires, S., Byrne, B. (eds.) Creating Breakthrough Ideas, Bergin \& Garvey, Foreword texts (2002)

2. Buur, J., Soendergaard, A.: Video Card Game: An Augmented environment for Use Centered Design discussions (2001)

3. Kushi, K.: Innovation notameno Design Process, ed. Research Institute of Human Engineering for Quality Life, Maruzen, pp. 104-115 (2005) (in Japanese)

4. Kawakita, J.: Hassou-Hou, Chuou-Shinsho, Chuou-Kouron-Shinsha (1967) (in Japanese) 